\title{
O efeito do laser de baixa energia no crescimento bacteriano "in vitro"*
}

\section{Low level laser effect in "in vitro" bacterial growth}

\author{
Fernando Coutinho', Vincenzo Giordano ${ }^{2}$, Carolina Mariano dos Santos ${ }^{3}$, Abel Ferreira Carneiro4, \\ Ney Pecegueiro do Amaral ${ }^{5}$, Maria Cristina Touma ${ }^{6}$, Marcos Giordano ${ }^{7}$
}

\section{RESUMO}

Objetivo: Avaliar, por meio de estudo bacteriológico in vitro, o efeito de dois tipos de laser de baixa energia (LBE) sobre diferentes populações bacterianas habitualmente presentes em feridas pós-traumáticas. Métodos: Foram colhidos swabs diretamente do sítio de infecção de pacientes internados com osteomielite pós-traumática crônica. As bactérias isoladas foram Acinetobacter baumanii complex,

* Investigação realizada no Serviço de Ortopedia e Traumatologia do Hospital de Ipanema, no Serviço de Ortopedia e Traumatologia do Hospital Municipal Miguel Couto e no Laboratório de Análises Clínicas do Hospital Municipal Miguel Couto, Rio de Janeiro (RJ), Brasil.

1. Médico Ortopedista Estagiário do Grupo de Coluna do Instituto Nacional de Tráumato Ortopedia - INTO - e de Clínica Particular - Rio de Janeiro (RJ), Brasil.

2. Médico Assistente e Coordenador do Programa de Residência Médica do Serviço de Ortopedia e Traumatologia - Hospital Municipal Miguel Couto - Rio de Janeiro (RJ), Brasil.

3. Médico Residente do Serviço de Ortopedia e Traumatologia - Hospital de Ipanema - Rio de Janeiro (RJ), Brasil.

4. Médico Ortopedista de Clínica Particular - Rio de Janeiro (RJ), Brasil.

5. Chefe do Serviço de Ortopedia e Traumatologia - Hospital Municipal Miguel Couto - Rio de Janeiro (RJ), Brasil.

6. Bióloga e Técnica do Laboratório de Análises Clínicas do Hospital Municipal Miguel Couto - Rio de Janeiro (RJ), Brasil.

7. Médico Ortopedista, Coordenador de Residência Médica do Hospital da Força Aérea do Galeão - Rio de Janeiro (RJ), Brasil.

Endereço para correspondência: Dr. Fernando Coutinho, Av. N. Sa de Copacabana, 664/808, Copacabana - 22070-000 - Rio de Janeiro, RJ. Tel./fax: (21)

2548-6549. E-mail: fernando_dario_coutinho@hotmail.com

Recebido em 19/10/06. Aprovado para publicação em 14/8/07.

Copyright RBO2007
Escherichia coli, Haemophilus influenzae, Klebsiella pneumoniae, Pseudomonas aeruginosa, Salmonela sp, Serratia sp e Staphylococcus aureus. O material coletado foi semeado em meio ágar-sangue, através de alça estéril, utilizando-se 30 placas de Petri para cada germe. Foram utilizados dois aparelhos de LBE: Ibramed Laser Pulse \#01189, com 15W/904nm por 200 segundos, e Phisiolux dual Bioset \#9909001, com $20 \mathrm{~W} / 904 \mathrm{~nm}$ por 230 segundos. Nos grupos I $(n=10)$ e II $(n=10)$, as bactérias sofreram irradiação pelo laser. $O$ grupo III $(n=10)$ serviu de controle, não sendo irradiado. As bactérias dos grupos I e II foram irradiadas em câmara de fluxo laminar, previamente esterilizada por raio ultravioleta. $O$ laser foi administrado de forma direta, central e perpendicularmente à superfície de cultivo das bactérias, com distância-padrão de $1 \mathrm{~cm}$, através de orifício confeccionado na tampa das placas. $O$ crescimento bacteriano foi analisado após 12 e 24 horas da irradiação. Os resultados foram processados estatisticamente, utilizando-se o teste não-paramétrico de KruskallWallis, com nível de significância $\mathrm{p}<5 \%$. Resultados: $\mathrm{Ob}$ servou-se comportamento similar entre as populações bacterianas nos três grupos experimentais após 12 e 24 horas da irradiação com os dois tipos de LBE, não havendo diferença estatisticamente significante no crescimento bacteriano entre os grupos I e II e entre estes e o grupo III (controle). Conclusão: $\mathrm{O}$ efeito do LBE, nas condições estudadas, mostrou-se inócuo quanto ao aumento do número de unidades formadoras de colônias bacterianas, nas doses utilizadas nesta pesquisa, como medida adjuvante no processo de cicatrização de feridas, mesmo na vigência de contaminação pelas bactérias avaliadas.

Descritores - Infecção da ferida operatória; Crescimento bacteriano; Análise bacteriológica; Contaminação; Lasers/métodos 


\section{ABSTRACT}

Objecive: To perform an in vitro bacteriologic study to evaluate the effect of two types of low level laser (LLL) on different bacterial populations usually present in posttraumatic wounds. Methods: Swabs were prepared directly at the infection site of patients hospitalized with chronic posttraumatic osteomyelitis. Isolated bacteria were Acinetobacter baumanii complex, Escherichia coli, Haemophilus influenzae, Klebsiella pneumoniae, Pseudomonas aeruginosa, Salmonela sp, Serratia sp, and Staphylococcus aureus. The material collected was seeded in agar-blood medium with a sterile loop, using 30 Petri dishes for each germ. Two LLL devices were used: Ibramed Laser Pulse \#01189, with 15W/904nm for 200 seconds, and Phisiolux dual Bioset \#9909001, with 20W/904nm for 230 seconds. In groups I $(n=10)$ and II $(n=10)$, bacteria were irradiated with laser. Group III $(n=10)$ was the control group and was not irradiated. Bacteria in groups I and II were submitted to radiation in a laminar flow chamber that was previously sterilized with UV rays, and the laser was directly, centrally, and perpendicularly applied to the bacteria cultivation surface, from a standard distance of one centimeter, through an orifice made in the lid of the dishes. Bacterial growth was analyzed 12 and 24 hours after the irradiation. Results were statistically processed using the non-parametric test of Kruskall-Wallis, with a significance level $p<5 \%$. Results: A similar behavior was seen in the bacterial population of the three groups studied after 12 and 24 hours of irradiation with the two types of LLL, and there was no statistically significant difference in the bacterial growth between groups I and II and between these two groups and group III (control). Conclusion: In the conditions of this study, the effect of LLL showed to be innocuous for the increase in the number of units forming bacterial colonies, in the doses used in this study, as an adjuvant for the wound healing process, even under contamination by the bacteria being evaluated.

$\begin{aligned} \text { Keywords - } & \text { Surgical wound infection; Bacterial growth; } \\ & \text { Bacteriological analysis; Contamination; Lasers/ } \\ & \text { methods }\end{aligned}$

\section{INTRODUÇÃO}

Recentemente, a utilização do laser de baixa energia (LBE) vem sendo pesquisada por inúmeros autores como medida adjuvante na cicatrização de feridas de partes moles ${ }^{(1-6)}$. Em teoria, sua capacidade de biomodularidade sobre o processo de cicatrização cutânea ocorreria principalmente durante a fase proliferativa, devido ao aumento do metabolismo celular local à custa de hiperregulação mitocondrial ${ }^{(3,5)}$. Capon et al observaram melhora significante no aspecto cosmético e na velocidade de cicatrização de incisões cutâneas infligidas experimentalmente em cobaias ${ }^{(1)}$. Tem sido sugerido que o LBE aumenta o metabolismo celular, estimula a fosforilação oxidativa e reduz a resposta inflamatória local, alterando positivamente as propriedades eletrofisiológicas do tecido irradiado $^{(1-6)}$. Estudos in vitro de culturas de queratinócitos revelaram que o LBE estimula a liberação de citocinas (IL-6 e IL-8) e fatores de crescimento e diferenciação (FGF - fibroblast growth factor) envolvidos no processo de reparo cutâneo ${ }^{(5,7)}$.

A aplicação do LBE no processo de cicatrização de feridas parece ser interessante e promissor; entretanto, seu uso no manejo de extensas lesões de tecidos moles com imputada contaminação bacteriana não foi, ainda, objeto de investigação adequada. A influência do LBE sobre a modulação fenotípica de diferentes populações bacterianas tem sido pobremente discutida na literatura, em geral utilizando modelos in vitro e experimentações clínicas em odontologia e dermatologia ${ }^{(8-13)}$. Nussbaum et al observaram crescimento in vitro de bactérias expostas à irradiação com LBE de 810nm de comprimento de onda e frequiência de $1.000 \mathrm{~Hz}^{(11)}$. Contraditoriamente, Meral et al relataram redução no número de unidades formadoras de colônia em cinco espécies de bactérias submetidas in vitro à irradiação com laser Nd-YAG, sugerindo que seu efeito bactericida reduziria o risco de infecção em feridas pós-operatórias $^{(10)}$.

O objetivo dos autores foi avaliar, por meio de estudo bacteriológico in vitro, o efeito de dois tipos de LBE sobre diferentes populações bacterianas presentes em feridas pós-traumáticas.

\section{MÉTODOS}

Foram colhidos fragmentos ósseos e swabs diretamente do sítio de infecção, após limpeza adequada da pele ao redor da ferida pós-operatória, de pacientes internados com osteomielite pós-traumática nas enfermarias do Serviço de Ortopedia e Traumatologia do Hospital Municipal Miguel Couto, e o material estudado no Laboratório de Análises Clínicas do referido hospital. Os pacientes preencheram consentimento informado e o projeto foi enviado à aprovação da Comissão de Ética em Pesquisa da Secretaria Municipal de Saúde do Rio 
de Janeiro, de acordo com a Resolução 196/96 do Conselho Nacional de Saúde (Diretrizes e Normas Regulamentadoras de Pesquisa Envolvendo Seres Humanos) ${ }^{(14)}$. A relação das bactérias e os sítios de coleta do material infectado encontram-se no quadro 1.

\section{QUADRO 1}

Relação de bactérias e sítios de coleta do material infectado

\begin{tabular}{|ll|}
\hline \multicolumn{1}{|c|}{ Bactéria } & \multicolumn{1}{c|}{$\begin{array}{c}\text { Sítio de coleta do } \\
\text { material infectado }\end{array}$} \\
\hline $\begin{array}{l}\text { Staphylococcus aureus } \\
\text { Acinetobacter baumanii complex } \\
\text { Escherichia coli }\end{array}$ & $\begin{array}{l}\text { Fragmento ósseo femoral } \\
\text { Haemophilus influenzae }\end{array}$ \\
Klebsiella pneumoniae & Fístula em coxa \\
Pseudomonas aeruginosa & Fístula em perna \\
Salmonela sp. & Mal perfurante plantar \\
Serratia sp. & Fístula em perna \\
\hline
\end{tabular}

Fonte: Serviço de Ortopedia e Traumatologia e Laboratório de Análises Clínicas Hospital Municipal Miguel Couto, 2005.

O material coletado foi diluído separadamente dentro de tubos de ensaio (medindo $70 \mathrm{~mm} \times 10 \mathrm{~mm}$ ) em soro fisiológico a $0,45 \%$, após 24 horas do replique em placa de Petri em meio ágar-sangue. A concentração das bactérias em cada tubo de ensaio foi padronizada por meio de colorímetro, utilizando-se a escala de McFarland: ponteiro do colorímetro indicando cor vermelha para germes gram-positivos e cor azul para gram-negativos. A seguir, as bactérias foram semeadas em meio ágar-sangue mediante alça estéril. Foram utilizadas 30 placas de Petri para cada germe, divididas para o experimento da seguinte forma:

- Bactérias irradiadas pelo laser A (grupo I, $\mathrm{n}=10$ );

- Bactérias irradiadas pelo laser B (grupo II, $\mathrm{n}=10$ );

- Bactérias não irradiadas (grupo III - controle, $n=10$ ).

As bactérias contidas nas placas de Petri dos grupos I e II foram irradiadas simultaneamente, sempre pelo mesmo pesquisador, de forma cega. Foram utilizados dois aparelhos de LBE: A) Ibramed Laser Pulse ${ }^{\circledR} 01189$ (Amparo, São Paulo), com 15W/904nm por 200 segundos (laser A); B) Phisiolux dual Bioset ${ }^{\circledR}$ \#9909001 (Rio Claro, São Paulo), de radiação contínua, com 20W/904nm por 230 segundos (laser B). O experimento realizou-se em câmara de fluxo laminar, previamente esterilizada por raio ultravioleta. O laser foi administrado de forma direta, central e perpendicularmente à superfície de cultivo das bactérias, com distância-padrão de $1 \mathrm{~cm}$, através de orifício confeccionado na tampa das placas. Após a irradiação com o laser, as tampas foram trocadas por outra sem orifício. Em seguida, as placas dos grupos I, II e III das oito espécies de bactérias foram levadas à estufa.

A leitura das placas foi realizada após 12 e 24 horas da irradiação para contagem de unidades formadoras de colônias (UFC/ml). A análise foi sempre feita pelo mesmo pesquisador, de forma cega.

Os dados obtidos foram processados com o programa Statistica 6 (StatSoft, Inc., EUA), utilizando-se o teste não-paramétrico de Kruskall-Wallis, com nível de significância de 5\%.

\section{RESULTADOS}

Comportamento similar foi observado entre as populações bacterianas nos três grupos experimentais após 12 e 24 horas da irradiação com os dois tipos de LBE (figura 1). Os dados descritivos dos resultados estão demonstrados nas tabelas 1 (12 horas) e 2 (24 horas). Não houve diferença estatisticamente significante no crescimento bacteriano entre os grupos I e II e entre estes e o grupo III (controle) $(p>0,05)$. Por não haver variação nos resultados, não foi investigada a relação entre espécies bacterianas.

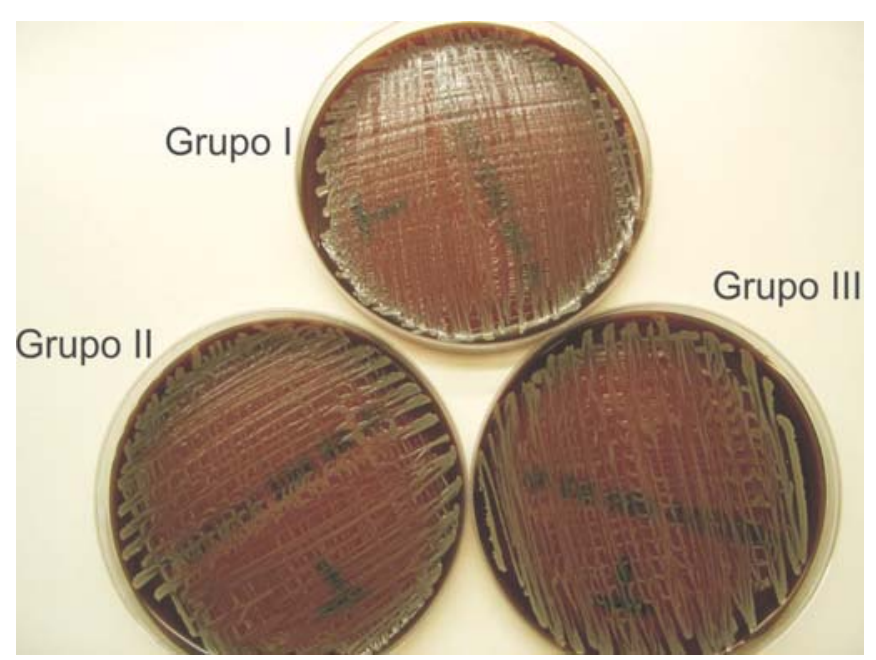

Figura 1 - Placas de Petri com Staphylococcus aureus em meio ágar-sangue demonstrando crescimento bacteriano similar entre os três grupos estudados 
TABELA 1

Unidades formadoras de colônias (UFC/ml) de microrganismos após 12 horas

\begin{tabular}{lccc}
\hline \multicolumn{1}{c}{ Bactéria } & Grupo I & Grupo II & Grupo III \\
\hline Staphylococcus aureus & 5,03 & 5,05 & 5,11 \\
Acinetobacter baumanii complex & 7,34 & 7,29 & 7,36 \\
Escherichia coli & 6,52 & 6,56 & 6,56 \\
Haemophilus influenzae & 6,21 & 6,24 & 6,27 \\
Klebsiella pneumoniae & 6,67 & 6,80 & 6,78 \\
Pseudomonas aeruginosa & 5,98 & 5,87 & 6,01 \\
Salmonela sp. & 7,02 & 6,98 & 7,03 \\
Serratia sp. & 5,87 & 5,93 & 5,93 \\
\hline
\end{tabular}

Fonte: Serviço de Ortopedia e Traumatologia e Laboratório de Análises Clínicas Hospital Municipal Miguel Couto, 2005.

TABELA 2

Unidades formadoras de colônias (UFC/ml) de microrganismos após $\mathbf{2 4}$ horas

\begin{tabular}{lccc}
\hline \multicolumn{1}{c}{ Bactéria } & Grupo I & Grupo II & Grupo III \\
\hline Staphylococcus aureus & 8,89 & 8,89 & 8,94 \\
Acinetobacter baumanii complex & 8,97 & 9,03 & 9,05 \\
Escherichia coli & 8,22 & 8,26 & 8,26 \\
Haemophilus influenzae & 8,90 & 8,88 & 8,91 \\
Klebsiella pneumoniae & 8,87 & 8,86 & 8,88 \\
Pseudomonas aeruginosa & 8,80 & 8,83 & 8,81 \\
Salmonela sp. & 9,01 & 8,94 & 9,03 \\
Serratia sp. & 8,69 & 8,72 & 8,73 \\
\hline
\end{tabular}

Fonte: Serviço de Ortopedia e Traumatologia e Laboratório de Análises Clínicas Hospital Municipal Miguel Couto, 2005.

\section{DISCUSSÃO}

A importância do LBE vem ganhando considerável reconhecimento na última década ${ }^{(15)}$. Suas possíveis aplicações clínicas, como modalidade terapêutica, em lesões de partes moles e de tecido ósseo, têm sido largamente estudadas. Conquanto não exista consenso com relação aos efeitos biológicos do LBE no processo de reparo ósseo, seu uso parece promissor no manejo adjuvante de lesões de tecidos moles, associadas ou não à fratura ${ }^{(1-7,16-17)}$. Seu efeito bioestimulante, que ocorre localmente, por aumento do metabolismo celular e por redução da resposta inflamatória, está diretamente associado ao estímulo da função mitocondrial e das células do sistema fagocítico mononuclear ${ }^{(3,6)}$.

Estudos recentes vêm documentando as vias envolvidas na geração de energia e na proteção antioxidante mediadas pela mitocôndria ${ }^{(18-19)}$. Tem sido sugerido que a função mitocondrial é estimulada pela sua elevada fotorrecepção à luz mono- cromática do laser ${ }^{(6,18)}$. Dessa maneira, os componentes da cadeia respiratória celular são ativados, controlando a fosforilação oxidativa, produzindo ácido nucléico e induzindo a proliferação celular por mitose ${ }^{(18-19)}$. Apesar disso, os exatos mecanismos biofísicos da irradiação do LBE a células bacterianas têm sido pobremente investigados, tornando controverso seu uso em situações de contaminação suspeita ou confirmada de ferimentos em partes moles ${ }^{(20)}$.

Nussbaum et al e Tiphlova et al propuseram que a resposta fotobiológica de um microrganismo à exposição à luz monocromática depende diretamente dos parâmetros da irradiação (comprimento de onda, intensidade e dose) e das condições de cultivo do germe ${ }^{(20-21)}$. Assim como ocorre nas células implicadas na gênese do processo de reparo tissular de partes moles, parece que a taxa de crescimento do microrganismo é modulada por sua capacidade de transporte e transferência de oxigênio ${ }^{(22)}$. Uma vez ativada, a cadeia respiratória da bactéria gera rapidamente um gradiente de $\mathrm{pH}$ através da membrana da célula, estimulando a divisão celular precoce ${ }^{(20-22)}$.

Meral et al investigaram in vitro os efeitos do laser Nd:YAG (comprimento de onda de $1.060 \mathrm{~nm}$ ) sobre populações de Bacteroides fragilis, Candida albicans, Neisseria, Staphylococcus aureus, Streptococcus $\alpha$-hemoliticcus e Streptococcus salivarius. As bactérias foram inoculadas e mantidas em meio ágar-sangue e irradiadas com várias dosagens. Esses autores notaram redução no número de microrganismos em todas as seis espécies investigadas, concluindo que o laser ND:YAG possui efeito bactericida, principalmente na presença de alta concentração de hemoglobina (meio ágar-sangue) ${ }^{(10)}$. Nussbaum et al compararam os efeitos do LBE de 630, 660, 810 e $905 \mathrm{~nm}$ com radiação contínua e diferentes intensidades no crescimento bacteriano in vitro ${ }^{(11,20)}$. Cepas de Staphylococcus aureus, Escherichia coli e Pseudomonas aeruginosa foram cultivadas em ágar, irradiadas com laser e incubadas por 20 horas. Os autores observaram crescimento bacteriano com comprimento de onda de $810 \mathrm{~nm}$ em todas as espécies estudadas e inibição de sua biossíntese com comprimento de onda de $630 \mathrm{~nm}$. Concluíram que, em feridas infectadas, a utilização do LBE deve ser precedida de precisa identificação do germe existente e da correta escolha da técnica de irradiação ${ }^{(11,20)}$. Schindl et al avaliaram o uso do LBE no tratamento de lesões ósseas e gangrena em dois pacientes portadores de microangiopatia diabética. Eles observaram, dentro de um período médio de 14 semanas, que houve cura completa das gangrenas diabéticas e restabelecimento radiográfico do padrão cortical, com mineralização da lesão óssea preexistente. Schindl et al concluíram que o LBE deve ser mais estudado como uma 
modalidade terapêutica para a cura da gangrena e lesões ósseas em pacientes diabéticos ${ }^{(12)}$. Schoop et al utilizaram 360 fragmentos de raiz de dentina, extraídos de pré-molares humanos, esterilizados e posteriormente introduzidos em suspensão contendo Enterococcus faecalis e Escherichia coli(13). Os frascos foram divididos aleatoriamente em quatro grupos e expostos à irradiação com quatro tipos de LBE, com comprimentos de onda diferentes. Estudo microbiológico indicou redução significante no número de bactérias com todos os tipos de laser empregados. Schindl et al concluíram que o uso do LBE é ferramenta útil na desinfecção de camadas profundas de dentina, devendo ser adotado na endodontia moder$\mathrm{na}^{(13)}$.

No presente experimento, os autores elaboraram desenho de pesquisa voltado para reproduzir, in vitro, condições comuns na prática ortopédica atual: presença de grande contaminação, comumente encontrada em lesões grosseiras de partes moles com ou sem exposição de tecido ósseo. Após 12 e 24 horas da irradiação, não foi notada diferença estatisticamente significativa no crescimento bacteriano entre os grupos experimentais. A nosso ver, dois pontos merecem atenção especial.

Conforme mencionado, a condição de cultivo é determinante para o crescimento do microrganismo ${ }^{(21)}$. Embora não totalmente compreendido após irradiação com laser, a participação de células hematopoéticas parece otimizar a reação de defesa do hospedeiro ${ }^{(9)}$. Entretanto, o fato de não haver diferença no crescimento bacteriano entre as placas de Petri irra-

\section{REFERÊNCIAS}

1. Capon A, Souil E, Gauthier B, Sumian C, Bachelet M, Buys B, et al.. Laser assisted skin closure (LASC) by using a 815-nm diode-laser system accelerates and improves wound healing. Lasers Surg Med. 2001;28(2): $168-75$.

2. Lilge L, Tierney K, Nussbaum E. Low-level laser therapy for wound healing: feasibility of wound dressing transillumination. J Clin Laser Med Surg. 2000;18(5):235-40.

3. Medrado AR, Pugliese LS, Reis SR, Andrade ZA. Influence of low level laser therapy on wound healing and its biological action upon myofibroblasts. Lasers Surg Med. 2003;32(3):239-44.

4. Mendez TM, Pinheiro AL, Pacheco MT, Nascimento PM, Ramalho LM. Dose and wavelength of laser light have influence on the repair of cutaneous wounds. J Clin Laser Med Surg. 2004;22(1):19-25.

5. Pereira AN, Eduardo C de P, Matson E, Marques MM. Effect of lowpower laser irradiation on cell growth and procollagen synthesis of cultured fibroblasts. Lasers Surg Med. 2002;31(4):263-7.

6. Reddy GK. Comparison of the photostimulatory effects of visible He-Ne and infrared Ga-As lasers on healing impaired diabetic rat wounds. Lasers Surg Med. 2003;33(5):344-51. diadas e as controle (não-irradiadas) parece refutar, em nosso estudo, a teoria de Meral et al, de que o laser possui elevado efeito bactericida na presença de alta concentração de hemoglobina ${ }^{(10)}$. A outra teoria, baseada na observação in vivo e in vitro de citocinas pró-inflamatórias liberadas após exposição celular ao $\mathrm{LBE}^{(7)}$, acreditamos não ser de possível avaliação em nosso experimento, pois o meio ágar-sangue não corresponde às condições in vivo.

A resposta fotoquímica da célula é dependente do comprimento de onda utilizado ${ }^{(6,21)}$. A ativação da cadeia respiratória por exposição a determinados comprimentos de onda de luz monocromática promove elevação local do gradiente de $\mathrm{pH}$, gerando fenômeno de gatilho para a duplicação da célula bacteriana ${ }^{(21)}$. Assim, como no presente experimento, em que foram utilizados aparelhos com comprimento de onda de $904 \mathrm{~nm}$, Nussbaum et al e Lee et al observaram efeito negativo, com redução significante do número de colônias de microrganismos, após irradiação com laser de $904 \mathrm{~nm}$, reforçando o pensamento de que existe uma "ação letal" que é dose-dependente do $\operatorname{LBE}^{(20,23)}$.

\section{CONCLUSÃO}

O efeito do LBE, nas condições estudadas, mostrou-se inócuo quanto ao aumento do número de unidades formadoras de colônias bacterianas, podendo ser utilizado, nas doses utilizadas nesta pesquisa, como medida adjuvante no processo de cicatrização de feridas, mesmo na vigência de contaminação pelas bactérias avaliadas.

7. Moore P, Ridgway TD, Higbee RG, Howard EW, Lucroy MD. Effect of wavelength on low-intensity laser irradiation-stimulated cell proliferation in vitro. Lasers Surg Med. 2005;36(1):8-12.

8. Kawamoto K, Senda N, Shimada K, Ito K, Hirano Y, Murai S. Antibacterial effect of yellow He-Ne laser irradiation with crystal violet solution on Porphyromonas gingivalis: an evaluation using experimental rat model involving subcutaneous abscess. Lasers Med Sci. 2000;15(4): 257-62.

9. Lapotko D, Romanovskaya T, Kutchinsky G, Zharov V. Photothermal studies of modulating effect of photoactivated chlorin on interaction of blood cells with bacteria. Cytometry. 1999;37(4):320-6.

10. Meral G, Tasar F, Kocagöz S, Sener C. Factors affecting the antibacterial effects of Nd:YAG laser in vivo. Lasers Surg Med. 2003;32(3):197-202.

11. Nussbaum EL, Lilge L, Mazzulli T. Effects of $810 \mathrm{~nm}$ laser irradiation on in vitro growth of bacteria: comparison of continuous wave and frequency modulated light. Lasers Surg Med. 2002;31(5):343-51.

12. Schindl A, Schindl M, Pernerstorfer-Schön H, Kerschan K, Knobler R, Schindl L. Diabetic neuropathic foot ulcer: successful treatment by lowintensity laser therapy. Dermatology. 1999;198(3):314-6. 
13. Schoop U, Kluger W, Moritz A, Nedjelik N, Georgopoulos A, Sperr W. Bactericidal effect of different laser systems in the deep layers of dentin Lasers Surg Med. 2004;35(2):111-6.

14. Ministério da Saúde. Conselho Nacional de Saúde. Comissão Nacional de Ética em Pesquisa. Normas para pesquisa envolvendo seres humanos (Res. CNS no 196/96 e outras). 2ae ed. ampliada. 1aㅡ reimpressão. Brasília: Ministério da Saúde; 2003.

15. Lucas C, Criens-Poublon LJ, Cockrell CT, de Haan RJ. Wound healing in cell studies and animal model experiments by Low Level Laser Therapy; were clinical studies justified? A systematic review. Lasers Med Sci. 2002;17(2):110-34.

16. Giordano V, Knackfuss IG, Gomes RC, Giordano M, Mendonça RG, Coutynho F. Influência do laser de baixa energia no processo de consolidação de fratura de tíbia: estudo experimental em ratos. Rev Bras Ortop. 2001; 36(5):174-8

17. Guzzardella GA, Fini M, Torricelli P, Giavaresi G, Giardino R. Laser stimulation on bone defect healing: an in vitro study. Lasers Med Sci. 2002; 17(3):216-20.
18. Eells JT, Wong-Riley MT, VerHoeve J, Henry M, Buchman EV, Kane MP, et al. Mitochondrial signal transduction in accelerated wound and retinal healing by near-infrared light therapy. Mitochondrion. 2004;4(5-6):55967.

19. Scheffler IE. A century of mitochondrial research: achievements and perspectives. Mitochondrion. 2001;1(1):3-31.

20. Nussbaum EL, Lilge L, Mazzulli T. Effects of 630-, 660-, 810-, and 905$\mathrm{nm}$ laser irradiation delivering radiant exposure of $1-50 \mathrm{~J} / \mathrm{cm}^{2}$ on three species of bacteria in vitro. J Clin Laser Med Surg. 2002;20(6):325-33.

21. Tiphlova O, Karu T. Action of low-intensity laser radiation on Escherichia coli. Crit Rev Biomed Eng. 1991;18(6):387-412.

22. Taylor BL. How do bacteria find the optimal concentration of oxygen? Trends Biochem Sci. 1983;8:438-41.

23. Lee P, Kim K, Kim K. Effects of low incident energy levels of infrared laser irradiation on healing of infected open skin wounds in rats. Laser Ther. 1993;5:59-64. 